Meta

Journal des traducteurs

Translators' Journal

\title{
Un caso de traducción identitaria: Le Petit Prince en andaluz
}

\section{David Marín Hernández}

Volume 64, numéro 1, avril 2019

URI : https://id.erudit.org/iderudit/1065329ar

DOI : https://doi.org/10.7202/1065329ar

Aller au sommaire du numéro

\section{Éditeur(s)}

Les Presses de l’Université de Montréal

ISSN

0026-0452 (imprimé)

1492-1421 (numérique)

Découvrir la revue

Citer cet article

Marín Hernández, D. (2019). Un caso de traducción identitaria: Le Petit Prince en andaluz. Meta, 64(1), 78-102. https://doi.org/10.7202/1065329ar

\section{Résumé de l'article}

Les différents dialectes d'une langue maintiennent des relations asymétriques. Parfois, une variété non dominante essaie de modifier sa position subordonnée en annulant son stigmate et en augmentant son prestige. La traduction peut devenir alors un mécanisme pour élever la catégorie de la variété stigmatisée : en traduisant une oeuvre canonisée dans la variété non dominante, il y a un transfert de capital symbolique depuis l'oeuvre originale vers la langue cible, de sorte que celle-ci puisse être considérée une langue de culture. Dans ce travail, nous étudierons la traduction de Le Petit Prince que Juan Porras a fait dans l'une des variétés les plus stigmatisées du dialecte andalou. Le but de cette traduction est de revendiquer cette variété et de la présenter comme le reflet d'une identité andalouse qui, selon le traducteur, a été aliénée durant des siècles par la colonisation castillane. En plus de décrire les caractéristiques linguistiques de cette traduction, nous analyserons les critiques dont elle a fait l'objet. Cette réception défavorable nous permettra d'évaluer le degré de conscience linguistique qui existe actuellement en Andalousie et de le comparer à celui d'autres communautés qui ont accueilli favorablement ce type de traductions revendicatives d'une identité nationale.
Ce document est protégé par la loi sur le droit d'auteur. L’utilisation des services d’Érudit (y compris la reproduction) est assujettie à sa politique d'utilisation que vous pouvez consulter en ligne.

https://apropos.erudit.org/fr/usagers/politique-dutilisation/ 


\title{
Un caso de traducción identitaria: Le Petit Prince en andaluz
}

\author{
DAVID MARÍN HERNÁNDEZ \\ Universidad de Málaga, Málaga, España \\ dmarin@uma.es
}

\section{RÉSUMÉ}

Les différents dialectes d'une langue maintiennent des relations asymétriques. Parfois, une variété non dominante essaie de modifier sa position subordonnée en annulant son stigmate et en augmentant son prestige. La traduction peut devenir alors un mécanisme pour élever la catégorie de la variété stigmatisée: en traduisant une œuvre canonisée dans la variété non dominante, il y a un transfert de capital symbolique depuis l'œuvre originale vers la langue cible, de sorte que celle-ci puisse être considérée une langue de culture. Dans ce travail, nous étudierons la traduction de Le Petit Prince que Juan Porras a fait dans l'une des variétés les plus stigmatisées du dialecte andalou. Le but de cette traduction est de revendiquer cette variété et de la présenter comme le reflet d'une identité andalouse qui, selon le traducteur, a été aliénée durant des siècles par la colonisation castillane. En plus de décrire les caractéristiques linguistiques de cette traduction, nous analyserons les critiques dont elle a fait l'objet. Cette réception défavorable nous permettra d'évaluer le degré de conscience linguistique qui existe actuellement en Andalousie et de le comparer à celui d'autres communautés qui ont accueilli favorablement ce type de traductions revendicatives d'une identité nationale.

\begin{abstract}
The different dialects of a language maintain asymmetric relationships. Sometimes, a non-dominant variety tries to modify its subordinate position by erasing its stigma and increasing its prestige. Translation can be used then as a mechanism for raising the category of a stigmatized variety: by translating a canonized work into the non-dominant variety, there is a transfer of symbolic capital from the prestigious work to the target language, which is trying to be considered as a language of culture. In this article we will study Juan Porras' translation of Le Petit Prince into one of the most stigmatized varieties of Andalusian dialect. The purpose of his translation is to endorse this variety and present it as the product of the Andalusian cultural identity, which, according to the translator, has been alienated for centuries by Castilian colonization. In addition to describing the linguistic characteristics of this translation, we will analyze the negative reviews it has received. This adverse reception will allow us to evaluate the degree of linguistic awareness that currently exists in Andalusia and to compare it with that of other speech communities that have welcomed this kind of activist translation supporting a national identity
\end{abstract}

\section{RESUMEN}

Las diferentes variedades dialectales de una lengua mantienen relaciones asimétricas. En ocasiones, los hablantes de una variedad estigmatizada tratan de alterar la relación de fuerzas deshaciéndose de su estigma e incrementando su prestigio lingüístico. La traducción constituye uno de los mecanismos que permite elevar la categoría de una variedad estigmatizada: al traducir una obra canonizada hacia la variedad no dominante, se produce una transferencia de capital simbólico desde la obra hacia la lengua de llegada, de manera que esta consigue presentarse como una lengua de cultura. En este trabajo estudiaremos la traducción de Le Petit Prince que Juan Porras ha realizado en una 
de las hablas andaluzas más estigmatizadas en España. El objetivo de esta traducción es reivindicar esta variedad y presentarla como el reflejo de una identidad andaluza alienada durante siglos por la colonización castellana, según el traductor. Además de describir las características lingüísticas de esta versión, analizaremos las críticas de las que ha sido objeto. Esta recepción tan adversa nos permitirá evaluar el grado de conciencia lingüística que existe actualmente en Andalucía y compararlo con el de otras comunidades de habla que sí han acogido favorablemente este tipo de traducciones reivindicativas de una identidad nacional.

\section{MOTS CLÉS/KEYWORDS/PALABRAS CLAVE/}

traduction et identité, langue pluricentrique, variété non dominante, andalou, Le Petit Prince

translation and identity, pluricentric language, non-dominant variety, Andalusian, The Little Prince

traducción e identidad, lengua pluricéntrica, variedad no dominante, andaluz, El Principito

\section{Introducción}

En comparación con la abundante bibliografía que se le ha dedicado al reto de trasladar a otra lengua los marcadores socioestilísticos presentes en el TO, sorprende la escasa atención que se le ha prestado a otra de las dificultades que la variación también le plantea al traductor: elegir la variedad más adecuada cuando se está traduciendo hacia una lengua pluricéntrica como la española, en la que coexisten múltiples estándares de prestigio surgidos en distintos países (Kloss 1967; Clyne 1992; Muhr 2016). Puesto que los receptores de una traducción hacia el español pueden pertenecer a múltiples comunidades de habla, el traductor ha de plantearse cuál es la variedad más adecuada para reescribir el texto original. Desgraciadamente, en la reflexión traductológica española, este asunto ha quedado marginado durante demasiado tiempo, pues se ha dado por sentado que, en la comunidad lingüística hispanófona, la variedad estándar que ha de utilizarse como lengua de traducción es la castellana, y ello no solo por parte de los traductores españoles, sino también entre los traductores hispanoamericanos. Y, de hecho, así ha sido durante mucho tiempo. Incluso en aquellas zonas en las que se ha generado una variedad alternativa a la castellana con el prestigio suficiente como para ser utilizada como lengua de distancia, se ha preferido seguir empleando el estándar español en los textos traducidos. Esto es lo que sucede, por ejemplo, entre los traductores argentinos. Aunque el empleo del pronombre vos (y su conjugación verbal correspondiente) está lo suficientemente extendido entre hablantes cultos de la variedad rioplatense, lo cierto es que se prefiere el pronombre tú en las traducciones de los autores clásicos (Bradford 2005: 323).

Sin embargo, aunque la lengua estándar española sea la variedad habitual en el ámbito de la traducción, en ocasiones los traductores recurren a otras variedades dialectales a modo de reivindicación de la identidad nacional simbolizada por el dialecto escogido, de ahí que se haya propuesto el término de traducciones identitarias o patrióticas para referirse a estas prácticas traductoras (Villena 2016: 90). Un ejemplo de este tipo de traducción identitaria nos lo ofrece el traductor Juan Porras ${ }^{1}$ en la reciente traducción (2017) que ha propuesto de Le Petit Prince ${ }^{2}$, el conocido relato del escritor Antoine de Saint-Exupéry. En lugar de recurrir a la variedad estándar española, el traductor malagueño ha reescrito el original francés en una de las 
hablas andaluzas ${ }^{3}$, concretamente la que se practica en la comarca de la Algarbía (Valle del Guadalhorce, provincia de Málaga), de la que es originario. Puesto que los rasgos más característicos de esta variedad dialectal se sitúan en el plano sonoro del lenguaje (al igual que los del resto de hablas andaluzas), el traductor se ha apartado de las normas ortográficas del español estándar tal como están codificadas por la Real Academia Española y ha optado por una ortografía alternativa que trata de reproducir gráficamente la pronunciación vernácula de los hablantes de esta comarca. El mismo título de la traducción le sirve a Juan Porras para mostrar las cartas desde la cubierta del libro: Er Prinzipito (Saint-Exupéry 1943/2017) ${ }^{4}$. Para disipar las posibles dudas que pudiera despertar esta ortografía, se ha añadido en la cubierta a pie de página la siguiente aclaración: «Andalú».

FIGURA 1

Cubierta de Er Prinzipito (Saint-Exupéry 1943/2017)

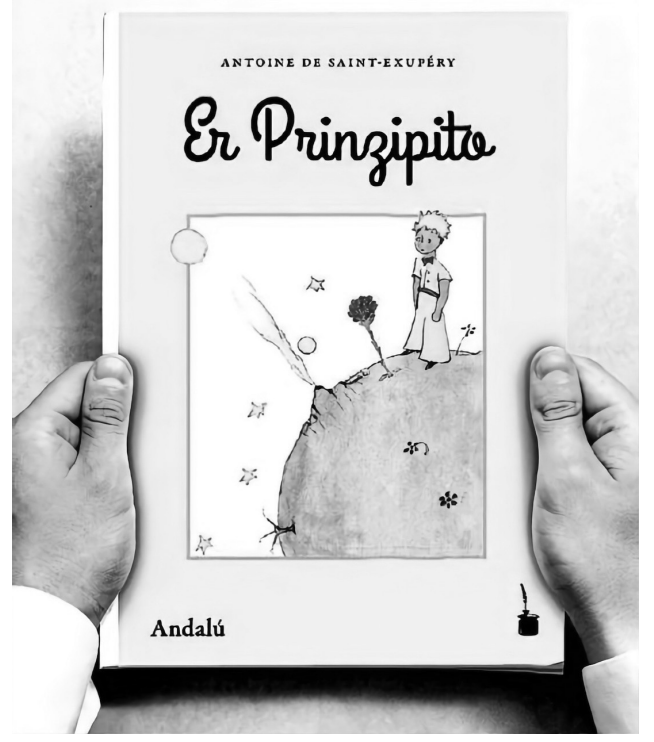

Así comienza el relato de Saint-Exupéry en la traducción de Juan Porras:

Una beh, kuando yo tenía zeih z'añiyoh, bi un dibuho mahnífiko en un libro a tento'e la zerba bihen ke ze yamaba Histoires Vécues (Ihtoria bibíah). En é ze figuraba a una bixa boa tragándoze una fiera. Ahkí de zegío ze be una kopia’e la imahen. En er libro rezaba: «Lah bixah boah ze tragan enterah a zuh prezah, zin mahkal-lah. Aluego ya no eh ehkapáe menearze i ze duerme de mientra ke le duran loh zeih mezeh de zu dihehtión. (Porras 2017: 9)

[Una vez, cuando yo tenía seis añillos, vi un dibujo magnífico en un libro acerca de la selva virgen que se llamaba Histoires Vécues (historias vividas). En él figuraba una bicha boa tragándose una fiera. Aquí a continuación se ve una copia de la imagen. En el libro rezaba: «Las bichas boas se tragan enteras a sus presas, sin mascarlas. Luego ya no es capaz de menearse y se duerme mientras le duran los seis meses de su digestión».]

La separación de la norma estándar española no es únicamente ortográfica. Algunas elecciones léxicas y morfosintácticas revelan igualmente la voluntad de utili- 
zar esta variedad dialectal en todos los niveles lingüísticos, ya que uno de los objetivos de este tipo de traducciones es demostrar que las variedades no estándares poseen la misma capacidad comunicativa y la misma riqueza literaria que la variedad ejemplar ante la que se presentan como alternativa. En última instancia, se trata de demostrar que la variedad que una comunidad ha elegido como estándar no es lingüísticamente más rica que las restantes variedades, pues esta elección está motivada fundamentalmente por razones extralingüísticas. Este tipo de traducciones trata de reaccionar contra una de las consecuencias inevitables de la existencia de una norma estándar codificada: la minusvaloración del resto de variedades, que se ven excluidas de los ámbitos oficiales o de la institución literaria y a las que se les suele negar la capacidad de ser utilizadas en las situaciones de distancia comunicativa (Milroy 2001). No es casual que la traducción de obras clásicas de la literatura universal sea uno de los instrumentos habitualmente elegidos para este propósito reivindicativo, pues lo que se persigue es una transferencia de capital simbólico (Bourdieu 1984) desde la obra original hacia el dialecto utilizado como lengua de llegada, que se presenta como una variedad capaz de reflejar la grandeza de una obra canónica.

La estrategia reivindicativa de Juan Porras se suma a la de otros traductores que también han apostado recientemente por apartarse del estándar castellano a la hora de reescribir a autores consagrados. Pensemos, por ejemplo, en el traductor argentino Miguel Ángel Montezanti, que ha ofrecido una versión de los sonetos de Shakespeare en la variedad que él denomina coloquial rioplatense (Montezanti 2011: 9). Aunque Montezanti (2011: 10) enmarque su versión en el concepto de parodia - «en el sentido amplio de la palabra que preconiza Linda Hutcheon en su ya clásico A Theory of Parody»-, lo cierto que es su propuesta también responde «a una cuestión de identidad [...] y de independencia cultural y lingüística» (Montezanti 2011: 26). No obstante, debemos ser cautelosos a la hora de trazar un paralelismo entre las traducciones de Juan Porras y Montezanti. Para empezar, la variedad empleada por este último sí se ha constituido en un estándar culto en su zona de influencia, a diferencia del habla andaluza utilizada por Juan Porras, que, lejos de ser considerada como una variante estándar entre los propios hablantes andaluces, está fuertemente estigmatiza en la propia Andalucía por los hablantes cultos. Además, la disidencia de Montezanti respecto del estándar no llega al extremo de alterar las normas ortográficas tal como ha hecho Juan Porras en su versión. Quizás esto explique la diferente recepción de la que han sido objeto ambas traducciones, ya que la ortografía es uno de los elementos de la codificación lingüística por el que los hablantes sienten un mayor apego y en el que se muestran más reacios a aceptar modificaciones. Mientras que la versión de Montezanti ha sido recibida calurosamente en Argentina ${ }^{5}$, las valoraciones que ha suscitado la traducción de Juan Porras, como se verá en las siguientes páginas, han oscilado en su mayoría entre la crítica y la burla, lo que supone un buen termómetro para medir el distinto grado de conciencia lingüística que existe en la sociedad argentina y andaluza respectivamente. En los países hispanoamericanos sí existe una identidad nacional que, desde la independencia en el siglo XIX, ha llevado a muchos hablantes a querer distanciarse de los usos lingüísticos de la antigua metrópoli (Fernando 2007: 173 y siguientes). Por el contrario, esta identidad lingüística no está tan marcada en la sociedad andaluza (Morillo-Velarde 2009: 198-199), ya sea porque las rivalidades internas entre distintos focos de poder político y económico han impedido asumir una única norma estándar que cohesione a los andaluces, ya 
sea porque el atraso económico de Andalucía en relación con el resto de España ha impedido la aparición de un sentimiento de secesión política o lingüística.

En este trabajo reflexionaremos sobre la ideología lingüística (Woolard 1998: 3; Irvine 1989: 255) y las reivindicaciones políticas que subyacen en la traducción de Juan Porras; analizaremos los procedimientos ortográficos, léxicos y gramaticales a los que ha recurrido el traductor y estudiaremos la recepción inicial de la que ha sido objeto esta traducción entre los propios hablantes andaluces, lo que nos permitirá asimismo llegar a algunas conclusiones acerca de la identidad lingüística de Andalucía en la actualidad.

\section{Traducciones identitarias}

No es infrecuente que las reivindicaciones lingüísticas asociadas a procesos de construcción nacional se hayan plasmado a través de traducciones. Uno de los mecanismos más efectivos para realzar el valor simbólico de una variedad lingüística consiste en utilizarla como lengua de llegada en la traducción de obras canonizadas. Recordemos, por ejemplo, que una de las razones por las que el castellano adquirió prestigio frente a otros romances peninsulares y acabó imponiéndose como base fundamental de la variedad coinética española fue el hecho de que las élites políticas, religiosas e intelectuales lo asumieron como una lengua de cultura, algo a lo que contribuyó la decisión de Alfonso x el Sabio de traducir las grandes obras de su tiempo en el romance castellano. Pero fue sobre todo durante el Renacimiento cuando muchos monarcas apostaron por promover la traducción en las lenguas romances para que estas se convirtieran en símbolos del sentimiento nacional que pretendían inculcar a sus súbditos. Las comunidades imaginadas (Anderson 1983) que constituían las modernas naciones necesitaban elementos que contribuyeran a generar la sensación de pertenencia a una misma comunidad, y nada mejor que compartir una misma lengua para experimentar este vínculo social. Cuando Francisco I promulgó el famoso edicto de Villers-Cotterêts para que todos los actos civiles se registraran en el francés vernacular (y no en latín), muchos textos comenzaron a ser traducidos en lengua francesa, que adquirió rápidamente el carácter de lengua nacional (Brisset 1990). Y lo mismo cabe decir de la lengua alemana a partir de la decisión de Lutero de traducir la Biblia «al alemán del pueblo» (Berman 1984: 46).

Si recordamos ahora estas traducciones históricas impulsadas por Alfonso x, por Francisco I o por Lutero es justamente para resaltar una de las grandes diferencias entre estos proyectos político-lingüísticos y la traducción en andaluz que propone ahora Juan Porras. Las traducciones medievales en el romance castellano o la traducción de la Biblia en alemán pretendían, entre otros objetivos, acercar los textos originales a una población que no podía acceder a la lengua latina, reservada a las élites sociales. Esta naturaleza comunicativa es justamente la que le falta a la traducción de Juan Porras: ningún andaluz necesita su traducción, pues todos los hablantes en Andalucía conocen y leen el castellano (lengua en la que ya existen varias traducciones de Le Petit Prince). Es más, la mayoría de andaluces se siente más cómoda leyendo en castellano (lengua en la que estos han sido escolarizados y que utilizan normalmente en la comunicación escrita) antes que en el andaluz algarbeño de Juan Porras, ya que esta habla local se circunscribe a un área geográfica muy concreta de Andalucía, de manera que ni su pronunciación ni todo su léxico son compartidos 
por el resto de andaluces. Así pues, la traducción de Juan Porras no tiene una función comunicativa, sino exclusivamente política: reivindicar una variedad dialectal andaluza que, en opinión del traductor, se encuentra oprimida por la colonización castellana de Andalucía6.

Así pues, al margen de la utilidad práctica de traducir, es evidente que las traducciones que se conciben como formas de resistencia adquieren una función ilocutiva distinta de la del texto original (Tymoczko 2010: 232-233). La función ilocutiva de la traducción de Juan Porras es alterar la relación de fuerzas entre dos variedades del español: la castellana -que constituye la base esencial sobre la que se ha construido el estándar nacional- y la andaluza, tradicionalmente subordinada e incluso estigmatizada entre muchos hablantes españoles. El impulso que ha motivado al traductor a proponer esta nueva versión de Le Petit Prince es la convicción de que los hablantes andaluces se encuentran alienados lingüística y culturalmente por la variedad ejemplar castellana, de ahí que ni siquiera sean conscientes de la violencia simbólica que están padeciendo al tener que expresarse a través de unas normas impuestas por un colonizador ajeno a la idiosincrasia andaluza. En estas circunstancias,

[t]ranslation becomes an act of reclaiming, of recentering of the identity, a re-territorializing operation. It does not create a new language, but it elevates a dialect to the status of a national and cultural language. (Brisset 1990: 346)

Nos encontramos, pues, ante un nuevo ejemplo de «instrumentalización de la traducción como metonimia de la diferencia, no solo entre lenguas, sino también entre culturas, etnias y naciones» (Jiménez 2012). La traducción de Juan Porras aspira a generar un efecto catártico entre los andaluces: trata de concienciarlos de que, aunque ellos todavía no lo sepan, son diferentes del resto de españoles, y pretende contribuir a la construcción de una identidad andaluza separada de la castellana a través del empleo de una variedad dialectal que supuestamente reflejaría (y, por ende, simbolizaría) una cosmovisión propia, esto es, una manera de ser esencialmente distinta de la castellana. Independientemente de que se compartan los presupuestos políticos de Juan Porras o su concepción humboldtiana de la lengua (propia del romanticismo nacionalista del siglo xIx), lo cierto es que su propuesta demuestra, una vez más, que «la traducción no es solamente la consecuencia de la diferencia babélica [...] sino que también es un elemento constitutivo de la identidad» (Jiménez 2012).

En este sentido, la traducción de Juan Porras nos recuerda a los autores quebequenses de los años setenta, quienes también desafiaron a la institución literaria de su país al recurrir a una variedad dialectal alejada del francés metropolitano para traducir obras clásicas de la literatura universal (Brisset 1990: 346). Al utilizar una variedad lingüística popular, estas traducciones tratan de diferenciarse todo lo posible del estándar culto: «La lengua es símbolo de identidad, tanto de integración en el grupo, como de alejamiento de este y de aspiración a la integración en otro u otros» (Villena 2000: 108; el énfasis es nuestro). El mensaje que los traductores envían a sus lectores se sustenta justamente en estas diferencias lingüísticas; se trata de demostrar que la identidad cultural de Quebec o de Andalucía es inexpresable a través del estándar francés o castellano, pues se parte del axioma de que una cultura solo puede ser transmitida a través de una única lengua propia que refleje la esencia del pueblo que la ha generado. Cuando se asumen estos presupuestos, la tarea del traductor se asemeja claramente a la del filólogo que tiene que rastrear el habla vernácula de los 
hablantes más puros, esto es, aquellos cuyo idiolecto no se haya visto contaminado por las instituciones colonizadoras que alteran el habla espontánea (sistema educativo, medios de comunicación, etc.). Esto explica que Juan Porras -al igual que los traductores quebequenses (Brisset 1990: 358)- haya recurrido en su traducción a un andaluz caracterizado por rasgos lingüísticos propios de hablantes rurales de estratos socioculturales bajos, ya que es en estos estratos donde más diferencias se encuentran en relación con el español estándar.

\section{La construcción de un andaluz puro}

Desde un punto de vista lingüístico, el rasgo más llamativo de la traducción de Juan Porras es su desafío a las normas ortográficas tal como están codificadas por la Real Academia Española. La ortografía de la RAE no permite reflejar por escrito la pronunciación de las hablas andaluzas, pues estas constituyen una modalidad lingüística altamente innovadora cuya disidencia del estándar castellano se plasma fundamentalmente en la pronunciación. Esta es la razón por la que Porras se ha visto en la necesidad de elaborar unas normas ortográficas propias para la transcripción del andaluz. Su objetivo, en última instancia, es de carácter etnográfico, ya que el propósito del traductor, según sus propias palabras, ha sido dejar constancia escrita de una tradición lingüística que, en su opinión, podría llegar a desaparecer ante el «empuje de la globalización y la españolización» (Porras 2009: 3) ${ }^{7}$. Resulta innecesario describir aquí de forma exhaustiva los detalles de esta propuesta ortográfica, ya que las normas pueden consultarse en el sitio web de la Sociedad para el Estudio del Andaluz ${ }^{8}$, a la que pertenece el traductor. Bastará citar ahora un breve fragmento de la traducción para hacerse una idea cabal de las profundas discrepancias con la ortografía estándar del español:

I dehe luego, en er planeta der prinzipito, komo en to loh planetah, abía yerbah guenah i yerbah malah. Por lo tanto, zemiyah guenah de yerbah guenah i zemiyah malah de yerbah malah. Pero lah zemiyah zon imbizibleh. Ehtán dormíah en er zekreto de la tierra ahta k'a arguna d'eyah ze l'antoha'e dihpertarze. Entoze ba ehtirazándoze pazia'r zó, mu manza al empieze, una grazioza matiya inofenziba. Zi ar kazo huera una matiya de rábano o de rozá, ze la pue dehà de krià komo’hkiera. Pero zi ze haya una mala planta, ai k’arrankà eza planta en kiantito ze la puea rekonozè. (Saint-Exupéry 1943/2017: 22)

[Y desde luego, en el planeta del principito, como en todos los planetas, había yerbas buenas y yerbas malas. Por lo tanto, semillas buenas de yerbas buenas y semillas malas de yerbas malas. Pero las semillas son invisibles. Están dormidas en el secreto de la tierra hasta que a alguna de ellas se le antoja dispersarse. Entonces va estirándose hacia el sol, muy mansa al principio, una graciosa matilla inofensiva. Si acaso fuera una matilla de rábano o de rosal, se la puede dejar crecer como quiera. Pero si se trata de una mala planta, hay que arrancar esa planta en cuanto se la pueda reconocer.]

Como puede observarse en el párrafo reproducido, una de las máximas en las que se inspira esta propuesta consiste en buscar la correspondencia unívoca entre los grafemas y los fonemas representados, de ahí que desaparezcan, por ejemplo, el grafema $\langle v\rangle$ y el dígrafo $\langle 11\rangle$ : el primero, por realizarse de forma bilabial en toda la comunidad de hispanohablantes, deja su lugar al grafema $\langle\mathrm{b}\rangle$; el segundo, debido al yeísmo mayoritario en Andalucía, se abandona a favor de letra $\langle y\rangle$. También desapa- 
rece, como es lógico, el grafema $\langle\mathrm{h}\rangle$ en aquellas palabras en las que no se realiza fonéticamente. Según explicó el propio traductor en la presentación del libro, otro de los criterios que ha guiado la codificación de estas normas es la búsqueda de la mayor sencillez posible para favorecer así la enseñanza y difusión de este sistema de transcripción ${ }^{9}$, de ahí que el fonema $/ \mathrm{k} /$ se transcriba siempre mediante el grafema $\langle\mathrm{k}\rangle$ (se prescinde, pues, del dígrafo $\langle q u\rangle$ y de la letra $\langle c\rangle$ ante las vocales $-\mathrm{a},-\mathrm{o},-\mathrm{y},-\mathrm{u})$, al igual que desaparece el dígrafo $\langle\mathrm{ch}\rangle$, que es sustituido por el grafema $\langle\mathrm{x}\rangle$ : hazían un efehto xulísimo [hacían un efecto chulísimo] (Saint-Exupéry 1943/2017: 58). En aras de reflejar de la forma más fiel posible la pronunciación, se utiliza también el apóstrofo para dejar constancia de múltiples tipos de contracciones propias del lenguaje oral: Z'imahinan k'okupan munxo sitio [se imaginan que ocupan mucho sitio] (SaintExupéry 1943/2017: 59). Aunque la mayoría de divergencias en esta propuesta ortográfica tienden a simplificar la ortografía estándar, se propone, sin embargo, el uso del acento grave (inexistente en la lengua española estándar) para acentuar las vocales finales de los infinitivos tras la pérdida de la -r implosiva: zumà i rehtà [sumar y restar] o intentà de komprendè [intentar comprender] (Saint-Exupéry 1943/2017: 29).

Ha de señalarse, en cualquier caso, que ni siquiera entre el colectivo minoritario de andaluces partidarios de escribir en andaluz existe unanimidad sobre cómo han de transcribirse los rasgos orales de esta modalidad lingüística. En efecto, el sistema desarrollado por Juan Porras pretende ante todo reproducir de la forma más fiel posible los rasgos orales de esta variedad dialectal, pero en el seno de la Sociedad para el Estudio del Andaluz existen propuestas ortográficas alternativas basadas en criterios etimológicos. Los propios promotores de estos sistemas de transcripción admiten el estado embrionario de sus iniciativas y la escasa difusión de estas normas entre los hablantes andaluces, de ahí que las planteen únicamente como propuestas iniciales para suscitar un debate entre los lingüistas comprometidos con la codificación de un andaluz estándar.

Aunque Juan Porras, en la presentación de este sistema de transcripción, subraye que lo ha concebido con la suficiente flexibilidad como para poder transcribir cualquier otra variedad andaluza, lo cierto es que todo proceso de codificación lingüística (especialmente en el terreno ortográfico) supone inevitablemente una imposición sobre la libertad de los hablantes, de manera que si en un futuro lejano sus anhelos de estandarizar el andaluz acaban arraigando entre los hablantes de esta modalidad lingüística -pues a corto o medio plazo esto parece bastante improbable dado el escaso arraigo de su propuesta-, la flexibilidad de la que se hace gala en la actualidad resultaría inadecuada para sus propósitos. La existencia de un estándar artificial que se superponga sobre las variedades naturales de los hablantes implica la asunción de unas normas coercitivas. Esta es la paradoja inevitable que han de asumir quienes luchan contra un estándar lingüístico ya establecido en defensa de otras variedades desprestigiadas: el éxito de su reivindicación concluye habitualmente en la propuesta de un nuevo estándar que, a su vez, generará nuevas variedades perjudicadas por la elección, especialmente en una región como Andalucía, donde coexisten múltiples hablas divergentes.

La preocupación por reflejar la oralidad de su habla comarcal ha llevado al traductor a introducir en su versión de Le Petit Prince una serie de características fonéticas que reproducimos en el Anexo $1^{10}$. Aunque los elementos sonoros de la lengua (y su correspondiente transcripción ortográfica) son los más llamativos en la traduc- 
ción de Juan Porras, no este el único plano lingüístico en el que el traductor se aparta de la lengua estándar para tratar de reflejar las características del andaluz algarbeño. Desde un punto de vista morfológico y sintáctico, cabe mencionar igualmente un conjunto de procedimientos que figuran en el Anexo 2.

Muchos de los rasgos lingüísticos descritos en ambos anexos demuestran que la elección de la lengua de llegada no solo se ha realizado con criterios geográficos, sino también sociales. De todas las hablas andaluzas, el traductor ha elegido como lengua de llegada el andaluz de la comarca de la Algarbía, tal como él mismo señala en su prólogo. Esta precisión geográfica es muy necesaria porque, efectivamente, el andaluz es un dialecto polimórfico que presenta características muy diferentes en función de la zona de Andalucía donde se hable. Ahora bien, el carácter caleidoscópico de este dialecto no se debe únicamente a su distinta repartición geográfica, sino también a su heterogeneidad social, pues no todos los estratos socioculturales presentan los mismos rasgos de pronunciación, léxicos o morfosintácticos. En este sentido, además de la información geográfica que nos proporciona el traductor, es igualmente importante indicar algo que no se menciona en el prólogo: muchos de los rasgos a los que ha recurrido Juan Porras para traducir Le Petit Prince son propios de los estratos socioculturales más bajos (o de los registros más informales); es decir, rasgos que se observan con más frecuencia entre hablantes de zonas rurales sin apenas formación cultural. De hecho, muchos de estos rasgos son considerados vulgarismos entre los propios hablantes andaluces, que tratan de evitarlos en situaciones de distancia comunicativa y que, por ello, resultan muy llamativos en un texto literario que SaintExupéry concibió en un registro formal. Fijémonos, por ejemplo, en la traducción de las siguientes oraciones (el énfasis es nuestro):

1) Et je fus stupéfait d'entendre le petit bonhomme me répondre.

(Saint-Exupéry 1943: 9)

a) I me keé alobao al ehkuchà k'er xabá me rehpondía.

[Y me quedé alobado al escuchar que el chaval me respondía.]

(Saint-Exupéry 1943/2017: 12, traducido por Porras)

2) De nouveau je me sentis glacé.

(Saint-Exupéry 1943: 98)

a) Me gorbí a keà kuahao

[Me volví a quedar cuajado.]

(Saint-Exupéry 1943/2017: 86, traducido por Porras)

3) Maintenant va-t'en!

(Saint-Exupéry 1943: 96)

a) ¡Ahora hopo!

[iAhora jopo!]

(Saint-Exupéry 1943/2017: 84, traducido por Porras)

4) Et tes amis seront bien étonnés de te voir rire en regardant le ciel.

(Saint-Exupéry 1943: 100)

a) I tuh amigoh fliparán en kuantito te vean de reírte mirando par zielo.

[Y tus amigos fliparán en cuantito te vean reírte mirando para el cielo.]

(Saint-Exupéry 1943/2017: 88, traducido por Porras) 
5) Je me préparai à essayer de réussir, tout seul, une réparation difficile.

(Saint-Exupéry 1943: 8)

a) M’abié yo zolito pa zehlià una trabahoza reparación.

[Me avié yo solito para realizar una trabajosa reparación.]

(Saint-Exupéry 1943/2017: 11, traducido por Porras)

Las elecciones léxicas de estos ejemplos reflejan claramente que el nivel de lengua empleado por el traductor es mucho más bajo que el del texto original (alobao [alobado], kuahao [cuajado], flipar [flipar], etc.). No es una opción dialectal, sino sociolectal, pues algunas de las expresiones utilizadas por el traductor no son exclusivas de Andalucía, sino que son propias de estratos socioculturales bajos de cualquier lugar de España. Se reproducen a continuación algunos de los elementos léxicos que más sorprenden en la versión de Juan Porras, especialmente porque no reflejan el registro formal del relato original en lengua francesa:

- ehkaxarrao (Saint-Exupéry 1943/2017: 11), en lugar de estropeado;

- ehnortado (Saint-Exupéry 1943/2017: 44), en lugar de desorientado;

- turulatao (Saint-Exupéry 1943/2017: 64), en lugar de estupefacto;

- una pexá'e orah (Saint-Exupéry 1943/2017: 77), en lugar de muchas horas;

- hueraparte (Saint-Exupéry 1943/2017: 18), en lugar de aparte;

- xalaúra (Saint-Exupéry 1943/2017: 77) en lugar de locura; etc.

El traductor ha optado, en consecuencia, por privilegiar una variante vernácula de escaso prestigio tanto fuera como dentro de Andalucía. La reivindicación de Juan Porras no es solo en defensa del andaluz, sino también en defensa de las hablas más desprestigiadas, aquellas que son practicadas por los estratos sociales más desfavorecidos. El contenido político de esta traducción se manifiesta, por ejemplo, en algunas de las explicaciones que ofrece el traductor para justificar el sistema de transcripción que ha desarrollado. Así, por ejemplo, recomienda utilizar siempre la letra zeta para representar gráficamente cualquier realización de los fonemas sibilantes «porque el zezeo es más popular (en el sentido de humilde y más dinámico que el seseo) y encima también está mucho más reprimido» (Porras 2009: 3). Una vez más, la estrategia de Juan Porras recuerda especialmente a la ya utilizada por los traductores quebequenses antes mencionados, que también desafiaron las expectativas de lectores y espectadores cuando se atrevieron a utilizar el joual en sus traducciones teatrales.

\section{El principito secuestrado}

Independientemente de que se compartan estas reivindicaciones, lo cierto es que el método elegido para plantearlas presenta algunos problemas de traducción, ya que los rasgos lingüísticos a los que ha recurrido Juan Porras no solo no encajan con el registro del TO, sino que, además, estas expresiones habituales entre hablantes de estratos socioculturales bajos o en situaciones relajadas aparecen intercaladas en la propia traducción con otras palabras propias de un registro formal mucho más cuidado, como: ozerbó kabarmente [observó cabalmente] (Saint-Exupéry 1943/2017: 22). Si dejamos al margen la realización fonética de esta expresión (zezeo, intercambio de -l por -r, simplificación de la coda silábica en observó) y nos concentramos en el plano léxico, tanto el verbo observar como el adverbio cabalmente sorprenden en el 
discurso de alguien que, poco después, utiliza la expresión a la mehón (Saint-Exupéry 1943/2017: 24) en lugar de a lo mejor. Al emplear en todas y cada una de las oraciones el habla vernácula propia de situaciones de inmediatez comunicativa, el traductor no solo no ha tenido en cuenta que esta variedad encaja mal con la variante socioestilística que caracteriza a los personajes del relato francés, sino que genera incongruencias internas en los discursos de estos personajes en la propia traducción, ya que en ocasiones se expresan mediante vulgarismos y, justo a continuación -sin que el contexto haya variado-, lo hacen con expresiones propias de un registro más cuidado.

Todo apunta, pues, a que la fidelidad al tono empleado por Saint-Exupéry no ha figurado entre las prioridades del traductor. Parece, por el contrario, que el texto original ha sido utilizado como excusa para dotar de mayor alcance a la reivindicación política y lingüística que se lanza a través de la traducción. La notoriedad del relato francés, en efecto, le ha permitido al traductor alcanzar una repercusión mediática que difícilmente habría conseguido en una comunidad lingüística -la andaluza- poco receptiva, de momento, a las reclamaciones identitarias de Juan Porras. Retomando la expresión de Luise von Flotow, podríamos decir que estamos ante un secuestro del TO, es decir, una apropiación del texto original con el objetivo de utilizarlo para difundir una posición política (Von Flotow-Evans 1991, 1997). De hecho, en algunos momentos el lector tiene la impresión de que no está ante una traducción del francés hacia el andaluz, sino del castellano hacia el andaluz (como ha reconocido el propio traductor cuando, en algunas charlas con motivo de la presentación del libro, ha admitido que ha trabajado no solo con el texto original francés, sino que también ha tenido presentes otras traducciones en castellano). En este sentido, podría decirse que Juan Porras ha traducido a la contra, en el sentido de que la traducción ha perdido en este caso su función originaria, pues no aspira tanto a dar a conocer al Otro como a reforzar la identidad propia (Gentzler 2008: 46-47).

Otro de los efectos indeseados de recurrir a un dialecto en la traducción de un texto extranjero es la reubicación del relato en un entorno que no le corresponde. El dialecto, al estar fuertemente enraizado en una zona geográfica concreta (en este caso, en la comarca de la Algarbía), adquiere un alto poder simbólico para identificar dicha zona, por lo que se genera una inevitable anatopía al ponerlo en boca de personajes que no son originarios de Andalucía. Este efecto anatópico resulta especialmente llamativo porque el traductor ha mantenido en francés las escasas referencias culturales que aparecen en el relato original, como el título del libro que el narrador menciona en su primera frase: Histoires Vécues, o como la referencia a la antigua moneda francesa (francos), que también se mantiene tal cual en la traducción de Porras: E bihto una kaza ke bale zien mir frankoh (Saint-Exupéry 1943/2017: 20). Mientras que los realia de la historia apuntan a un entorno cultural francés, el material lingüístico remite inevitablemente a una región española muy concreta.

La traducción permite, así, poner de manifiesto una importante diferencia simbólica entre la lengua estándar y el dialecto. El estándar, al no estar vinculado geográficamente a ninguna región concreta, permite con más facilidad que el lector admita la inevitable ficción lingüística que supone toda traducción: estamos dispuestos a aceptar que el principito hable en español, inglés, alemán... aunque sepamos que es una creación de un novelista francés. En cuanto empezamos a leer las primeras páginas del relato, aceptamos la mentira que supone toda traducción y nos olvidamos rápidamente de ella para disfrutar del texto. Pero si el principito se expresa 
en variedades diatópicas del español, inglés, alemán... el lector no puede dejar de pensar en el desvío lingüístico que implica el dialecto: la disidencia respecto del estándar acapara la atención de la lectura.

\section{Recepción de Er Prinzipito: falta de apoyo social a un estándar andaluz}

La publicación de la traducción andaluza de Le Petit Prince tuvo una gran repercusión mediática, tanto en la prensa regional como nacional. Salvo excepciones, la mayoría de articulistas reaccionaron negativamente ante la iniciativa de Juan Porras. Resulta significativo que buena parte de las críticas adoptasen un tono de burla hacia esta traducción, lo que muestra del escaso valor simbólico que poseen las hablas andaluzas en el mercado lingüístico español ${ }^{11}$. Algunas de las valoraciones más adversas vinieron de profesores universitarios expertos en dialectología andaluza ${ }^{12}$, que criticaron la traducción por razones muy similares a las que se han observado en otros procesos de legitimación de variedades no estándar, como el alemán austriaco (Muhr 2013: 13-14). En el caso concreto de Er Prinzipito, las críticas más recurrentes reprochaban al traductor el haber presentado como andaluz lo que es sino un sociolecto propio de hablantes sin formación caracterizado por rasgos lingüísticos que los propios hablantes andaluces tienden a rechazar en contextos formales. Se le recriminó especialmente el hecho de que, al identificar la modalidad lingüística andaluza con los niveles de lengua más informales, Juan Porras estaba reforzando y contribuyendo a extender los peores prejuicios que ha padecido tradicionalmente el andaluz y los hablantes de este dialecto.

Una de las características por la que el andaluz suele ser identificado -y caricaturizado- constantemente en la literatura popular o en los medios de comunicación audiovisuales es la relajación articulatoria, que conlleva una tendencia simplificadora hacia la eliminación de las codas silábicas. Mientras que los dialectos centronorteños de la península se caracterizan por su naturaleza conservadora (es decir, se mantienen fieles al estándar y realizan fonéticamente los fonemas finales de las sílabas trabadas), los dialectos meridionales, como el andaluz, presentan rasgos innovadores que lo separan del estándar y producen la pérdida de consonantes finales para generar sílabas con terminación vocálica (lo que popularmente se conoce como comerse los sonidos). Esta fonofagia ha sido iconizada (Irvine y Gal 2000: 37-38) a través del clásico estereotipo que presenta al andaluz como alguien reacio al esfuerzo y al trabajo. A este prejuicio ha contribuido igualmente el tradicional retraso económico y social de Andalucía respecto de las demás regiones españolas. Como se ha visto en la descripción lingüística de Er Prinzipito, la mayoría de rasgos sonoros a los que ha recurrido Juan Porras en su traducción apuntan justamente a esta relajación articulatoria que figura en cualquier caricaturización del hablante andaluz.

Otro de los reproches que se le ha lanzado a la traducción es que el andaluz es un dialecto polimórfico que carece de la unidad interna suficiente como para poder presentar un estándar propio asumido por los hablantes andaluces. En otras palabras, aunque el español hablado en Andalucía es percibido dentro y fuera de esta región como una modalidad lingüística autónoma y diferente de otras variantes, no se ha generado un estándar culto en torno al cual se aglutinen todos los hablantes. En efecto, desde el siglo xvi el castellano hablado en el sur de la Península se distinguía claramente de las variedades centronorteñas (Cano 2009: 80-81). Numerosos documentos 
de la época permiten deducir, por ejemplo, que en estas fechas tan tempranas ya se había producido una reducción del repertorio fonético de los hablantes meridionales debido a la fusión de algunos sonidos sibilantes. Sin embargo, no hay testimonios que hagan pensar que existía por entonces una conciencia lingüística identitaria entre los propios hablantes andaluces: «A los andaluces se les reconocía, en especial, desde fuera, antes de que tengamos noticias de que se hubiera desarrollado entre ellos una forma peculiar de su hablar castellano»(Cano 2009: 88). Es cierto que en aquel momento la norma sevillana conseguía rivalizar con la norma toledana, pues el poder político y, sobre todo, económico que había adquirido la ciudad de Sevilla tras albergar la Casa de Contratación de Indias había convertido a la capital andaluza en el centro irradiador de una variante lingüística con el suficiente prestigio entre sus propios hablantes como para erigirse en alternativa a la de la Corte castellana (la disputa entre Juan de Valdés y Elio Antonio de Nebrija así lo atestigua). Ahora bien, a diferencia del romance castellano, la norma sevillana nunca llegó a cristalizar en una variante estándar codificada. Le faltó fundamentalmente el apoyo de las élites sociales (Cano 2009: 121). Durante los siglos XVI y XVII los escritores andaluces -al igual que el resto de dramaturgos y poetas de otras regiones españolas- optaron por utilizar la variante castellana como vehículo de expresión literaria, lo que demuestra hasta qué punto el castellano se había convertido ya en lengua de cultura compartida por los españoles (Lapesa 1988; Quilis 1992; Herreras 2006). Habrá que esperar hasta bien entrado el siglo xx, concretamente hasta los años de la Transición, para observar un verdadero movimiento político y social en Andalucía encaminado a reforzar la conciencia lingüística de las hablas andaluzas como hecho identitario.

En efecto, durante el periodo de transición política hacia la democracia, diversos medios de comunicación y partidos políticos andaluces mimetizaron el discurso nacionalista de regiones como Cataluña, País Vasco o Galicia. En estas tres comunidades bilingües, la existencia de una lengua propia distinta del castellano se esgrimía como prueba de una identidad cultural diferente de la del resto de España, pues se asumía que cada sistema lingüístico entraña una cosmovisión propia e inconmensurable. El hecho de que esta situación de bilingüismo se utilizase por parte de estas tres comunidades históricas para reclamar un trato diferencial llevó a otras regiones a emplear argumentos similares en relación con sus hablas locales o dialectos históricos (Narbona y Morillo 1987: 32). En aras de situarse en el mismo plano que estas otras comunidades históricas, la población andaluza fue objeto de una intensa campaña mediática de concienciación lingüística. Uno de los argumentos principales de los numerosos artículos de opinión publicados en la prensa regional insistía en que una presunta colonización castellana había usurpado la identidad de los andaluces. Esta supuesta colonización castellana era igualmente responsable de que los andaluces hubieran asumido los prejuicios negativos que existían en el resto de España sobre su propia modalidad lingüística, de ahí que esta campaña de concienciación se dirigiese igualmente a reivindicar el habla andaluza como uno de los pilares esenciales de la identidad regional (Méndez 2009: 227 y siguientes).

Pero ni siquiera todo este esfuerzo desplegado en su momento desde diversas instancias sociales para concienciar a los andaluces de su identidad lingüística propia ha conseguido suscitar en Andalucía el deseo o la necesidad de normalizar su modalidad lingüística mediante un proceso de codificación consciente y planificado (Cano 1997: 9). Son múltiples las razones que se han aducido para explicar esta ausencia de 
preocupación por una planificación lingüística que condujese al establecimiento de una norma alternativa a la española. Para empezar, la heterogeneidad de las hablas andaluzas obligaría a optar por una de ellas en detrimento de las restantes, lo cual implicaría un proceso de imposición que no sería bien aceptado por todos los hablantes. Solo el habla de Sevilla goza de suficiente prestigio como para erigirse en candidata a asumir la función de variante ejemplar, pero el área donde ha irradiado este prestigio se reduce a la Andalucía occidental. Los hablantes de la zona oriental difícilmente asumirían de buen grado la imposición de una variante dialectal que no sienten como propia. Antes el contrario, en la Andalucía oriental se ha observado que entre los hablantes jóvenes urbanos con estudios se está desarrollando una coiné interdialectal compuesta tanto por rasgos no estigmatizados de la modalidad lingüística andaluza como por rasgos del estándar nacional (Villena 2000). Este proceso de nivelación con el español estándar en ciudades como Granada, Málaga o Jaén hace aún más improbable que buena parte de los hablantes andaluces lleguen a sentir la necesidad de emprender un proceso de codificación que, al menos en la actualidad, solo es reivindicado por grupos minoritarios. De hecho, se han realizado estudios sobre el grado de identidad territorial en Andalucía (Del Pino y Bericat 1998) que señalan «que el sentimiento identitario regional disminuye conforme aumenta el nivel educativo y el estatus social, pues las clases altas medio-altas son más proclives a una identidad dual» (Méndez 2009: 220).

Las dificultades lingüísticas y las controversias sociopolíticas que supondría un intento de normalización del andaluz explican que ninguno de los gobiernos de la Junta de Andalucía que se han sucedido hasta el momento se haya ni siquiera planteado este objetivo. Dada esta heterogeneidad interna del español hablado en Andalucía -que convierte a esta región en una comunidad de habla dialectal divergente (Milroy 1992: 55-60; Villena 2008)-, es lógico que en el Estatuto de Autonomía no se recoja en ningún momento la posibilidad de normalizar las hablas andaluzas codificando un estándar andaluz de uso obligatorio en los medios de comunicación públicos o en los centros de enseñanza. Por el contrario, el Estatuto se limita a promover, de forma genérica, «la investigación, difusión y conocimiento de los valores históricos, culturales y lingüísticos del pueblo andaluz en toda su riqueza y variedad $»^{13}$ (artículo 12.3.2). Las autoridades educativas andaluzas se mueven entre dos polos que, con mejor o peor fortuna, intentan hacer compatibles: por un lado, tratan de que los docentes valoren y respeten la identidad lingüística y cultural de sus alumnos, pero, al mismo tiempo, no pueden obviar que las «fuerzas del mercado lingüístico obligan a que la enseñanza dote a los alumnos de formas lingüísticas no siempre coincidentes con las identitarias» (Méndez 2009: 287). Así pues, la enseñanza de la norma estándar española en Andalucía tiene como principal objetivo dotar a los estudiantes andaluces de la posibilidad de elegir la norma que les resulte más adecuada y eficaz en función del contexto comunicativo. No obstante, este desiderátum resulta con frecuencia difícil de conseguir, a juzgar por los estudios realizados sobre las diferentes estrategias que se han seguido para plasmarlo en los libros de texto escolares (Méndez 2003).

Los problemas que ha supuesto la promoción de las hablas andaluzas a través de los medios audiovisuales públicos surgen también de esta falta de un modelo de prestigio unánimemente aceptado por los hablantes de esta comunidad. Pese a que desde sectores minoritarios se insiste en la necesidad de establecer pautas de pronun- 
ciación para que los locutores contribuyan a la difusión de un estándar andaluz, la guía de estilo de la radio televisión pública andaluza se limita a ofrecer

una descripción muy simplificada de formas de pronunciar que coexisten dentro de un espacio de variación y, a lo sumo, consejos para evitar ciertos vulgarismos, sean generales del español o específicos del andaluz. (Méndez 2009: 280)

Las críticas a la traducción de Juan Porras por parte de amplios sectores de la opinión pública andaluza contrastan con la actitud que adoptó esta misma opinión pública durante los años de la Transición ante las campañas a favor de la identidad lingüística en Andalucía. Mientras que durante los años ochenta lo habitual en la prensa regional era ensalzar el discurso identitario y subrayar el hecho diferencial lingüístico, en la actualidad, como se ha señalado en las páginas anteriores, se ha reaccionado de forma virulenta contra una traducción que, en última instancia, no deja de ser más que la expresión de muchas de las ideas que se defendieron durante los años ochenta por parte de no pocos medios de comunicación andaluces. La evolución de las circunstancias sociopolíticas en el conjunto de España podría explicar esta diferencia tan llamativa. Téngase en cuenta que aquella campaña de concienciación lingüística se desplegó durante la transición hacia la democracia. Tras cuarenta años de una dictadura que había potenciado una concepción homogénea y esencialista de la identidad española, la exaltación de lo diferente en la España de las autonomías se sentía como un signo de progreso político, pues suponía una ruptura con el pasado franquista. Además, la defensa de la identidad cultural andaluza durante la Transición debe enmarcarse en las negociaciones de Andalucía con el Estado central para conseguir los mismos derechos que otras comunidades históricas, por lo que no debe descartarse que el discurso identitario que se asumió en esta región formara parte de una estrategia más política que lingüístico-cultural: se trataba de concienciar a la población andaluza para que esta actuara como mecanismo de presión al Gobierno central.

Sin embargo, las circunstancias políticas que han rodeado más recientemente la publicación de la traducción de Juan Porras son bien diferentes. Cabe destacar, especialmente, que esta traducción ha visto la luz en uno de los momentos más álgidos del movimiento secesionista catalán, rechazado frontalmente por la mayoría de la población andaluza. Dado que la propuesta ortográfica de Juan Porras supone un desafío frontal al estándar normativo español, esta traducción ha sido vista por no pocos andaluces como un intento de secesión lingüística, $y$, tal como han señalado diversos investigadores,

los andaluces, como el resto de los hispanohablantes, no tienen el menor interés en quedarse descolgados del movimiento que conduce al fortalecimiento de la unidad y del peso (incluido el económico) del español en el mundo. (Narbona 2009: 55)

En definitiva, esta traducción de Er Prinzipito se ha vinculado con un nacionalismo identitario $^{14}$ del que la sociedad andaluza se siente mayoritariamente ajena.

\section{Conclusiones}

La estrategia lingüística de Juan Porras al traducir en andaluz Le Petit Prince encaja bien en el concepto de hipervernacularización, tal como ha sido propuesto por Trudgill $(1983,2003)$, pues estamos ante el uso de formas no estándar en una situa- 
ción comunicativa (traducción de un clásico de la literatura universal) en la que cabría esperar el uso de la forma estándar. Se trata, en definitiva, de una estrategia mediante la cual un hablante aspira a construirse una imagen social que lo vincula con los estratos socioculturales bajos. Para ello, recurre a mecanismos lingüísticos habituales en aquellas variantes vernaculares que se practican en dichos estratos ${ }^{15}$. El empleo consciente de esta modalidad de habla andaluza nos demuestra que los hablantes no son meros autómatas que se limitan a reproducir en su discurso las variantes lingüísticas que les corresponden estadísticamente en función de una serie de parámetros sociales que les vienen impuestos (lugar de nacimiento, clase social, etc.). Por el contrario, parece más bien

que la variación estilística es consecuencia del ejercicio activo (agency) de selección diseñado por el hablante en función de un conjunto multidimensional de factores (externos: audiencia, tema, situación; internos: propósito, clave, marco). (Villena 2016: 26; cursivas en el original)

Estos modelos de diseño del hablante (Coupland 2001; Eckert y Rickford 2001; Schilling-Estes 2002) inciden en la capacidad creativa de los hablantes para construir y transmitir una determinada imagen social a través de las variedades socioestilísticas elegidas conscientemente. Resulta interesante escuchar la forma de expresarse de Juan Porras en una de las entrevistas radiofónicas que concedió a raíz de la controversia generada por la publicación de su traducción ${ }^{16}$. Llama especialmente la atención que en esta entrevista el traductor andaluz respondiese a las preguntas del entrevistador siguiendo un patrón de pronunciación castellano, muy diferente de la realización oral que propone en Er Prinzipito.

La construcción de la máscara socioestilística con la que preferimos mostrarnos ante los demás depende no solo de factores situacionales, sino también de la ideología lingüística que, consciente o inconscientemente, profesamos. Aunque tras la publicación de Er Prinzipito la prensa insistió especialmente en las vinculaciones de Juan Porras con la izquierda independentista andaluza, nos interesa ahora destacar la ideología lingüística de la autenticidad que subyace en esta traducción (Woolard 2007). La comparación entre Le Petit Prince y su traducción en andaluz ha demostrado que los procedimientos lingüísticos a los que ha recurrido Juan Porras en Er Prinzipito no responden a una preocupación por reflejar fielmente el tono del TO, sino que buscan ante todo recrear la esencia auténtica de una comunidad de habla (la algarbeña, en el caso concreto que nos ocupa). La voluntad del traductor por distanciarse sistemáticamente de la lengua estándar refleja la ideología lingüística propia del romanticismo decimonónico que vinculaba las nociones de lengua, pueblo y nación. Ante el objetivo de encontrar la voz pura que surge de unas coordenadas geográficas muy concretas, poco importa cuál sea el tono empleado por SaintExupéry en el relato francés que se está traduciendo. En este tipo de traducciones identitarias, no es tan importante lo que se dice sino cómo se dice, pues la función referencial de la lengua queda ensombrecida por su función social: «Invocando un esquema semiótico, podemos decir que en este sistema ideológico prima la función pragmática de la deixis social sobre la referencia semántica» (Woolard 2007: 132). Así se explica, por ejemplo, el empleo que hace el traductor del llamado gerundio preposicional (véase anexo 2), que en la actualidad se documenta sobre todo en la lengua rural o en textos con una deliberada voluntad arcaizante; dos ingredientes -lo rural y lo arcaizante- que resultan esenciales en la ideología de la autenticidad lingüística. 
Si las variedades dialectales remiten a ubicaciones geográficas precisas $-y$, en ocasiones, a estratos sociales muy concretos-, la variedad estándar de la lengua, por el contrario, se presenta como un sistema lingüístico anónimo, depurado de cualquier connotación social, espacial o temporal: es una lengua sin ataduras que, por ello, tiende a ser utilizada no solo en situaciones de distancia comunicativa, sino también, y esto es lo que nos interesa ahora, en las traducciones de la literatura extranjera. Cuando un autor extranjero canonizado nos habla en español, su voz se acepta más fácilmente si lo hace en un español de ningún lugar, a través de una voz «desarraigada y universal, no localizada» (Woodar 2007: 133). Son muchos los instrumentos a través de los cuales las variedades estándares de las lenguas consiguen este blanqueo lingüístico que las presenta como sistemas de comunicación puros. Y todos ellos apuntan en la misma dirección: hacer olvidar al hablante que, en realidad, la lengua estándar es también, al igual que el resto de variedades, la lengua de un grupo social concreto. La diferencia radica en que este grupo ha conseguido borrar el origen social de su lengua, de manera que el resto de hablantes la asumen como una lengua puramente denotativa. Esta méconnaissance (Bourdieu 1984) del origen social de la lengua estándar es justamente lo que ponen en cuestión aquellas traducciones que, como la de Juan Porras, desafían la institución literaria al emplear variedades estigmatizadas. La tarea filológica que ha realizado el traductor a la hora de reconstruir el habla andaluza de Er Prinzipito puede ser cuestionada por los mecanismos lingüísticos que se presentan como andaluces sin serlo; como también pueden rebatirse, desde una perspectiva traductológica, las equivalencias que propone para el texto de Saint-Exupéry, pues los coloquialismos y vulgarismos empleados en Er Prinzipito no reflejan bien el tono formal empleado por el autor francés. Sin embargo, la propuesta de Juan Porras contribuye a plantear el debate sobre la variedad más adecuada para traducir hacia una lengua pluricéntrica como la española. No se trata de abandonar por sistema el estándar culto como lengua de traducción, sino de dejar de asumirlo como opción transparente e incuestionada.

\section{AGRADECIMIENTO}

Este trabajo se ha realizado en el marco del Proyecto de Investigación «La traducción de clásicos en su marco editorial: una visión transatlántica», financiado por el Ministerio de Economía y Competitividad (referencia FFI2013-41743-P).

\section{NOTAS}

1. Juan Porras es licenciado en Filosofía por la Universidad del País Vasco y doctor en Antropología Social por esta misma universidad. Desde 2008 imparte clase de cultura andaluza en el Departamento de Antropología Social de la Universidad Pablo de Olavide de Sevilla.

2. Saint-Exupéry, Antoine de (1943): Le Petit Prince. Nueva York: Reynal and Hitchcock. Citamos por la edición de 1972 (París): SAInt-Exupéry, Antoine de (1943/1972): Le Petit Prince. París: Gallimard.

3. La traducción se realizó a iniciativa de la editorial alemana Tintenfass, especializada en la traducción de Le Petit Prince a lenguas minoritarias y variedades dialectales de todo el mundo.

4. SAInt-Exupéry, Antoine de (1943/2007): Er Prinzipito. (Traducido del francés por Juan Porras BLANCO) Neckarsteinach: Tintenfass.

5. Zaro Vera, Juan Jesús (15 de noviembre de 2011): Solo vos sos vos. El Trujamán. Consultado el 21 de agosto de 2017, <http://cvc.cervantes.es/trujaman/anteriores/noviembre_11/15112011.htm>.

6. Otros ejemplos de traducciones identitarias sin función comunicativa nos los ofrecen Sontag (1997) acerca de una traducción de Esperando a Godot en serbocroata y bosnio, o, en la combinación 
castellano-catalán, Bacardí (2010). BACARDí, Monserrat (2010): La traducción del castellano al catalán en el siglo xx. Esbozo de una historia accidentada. Visat. Consultado el 21 de agosto de 2017, <http://www.visat.cat/articles/esp/20/la-traduccion-del-castellano-al-catalan-en-el-siglo-xx. esbozo-de-una-historia-accidentada.html>.

7. Porras, Juan (2009): Normas ortográficas para la transcripción del andaluz. Zoziedá pal Ehtudio’el Andalú. Consultado el 21 de agosto de 2017, <http://www.zea-andalu.com/empieze/propuehtahortogr\%C3\%A1fikah/>.

8. Zoziedá pal Ehtudio’el Andalú. Consultado el 21 de agosto de 2017: <http://www.zea-andalu.com/>.

9. Marroco (14 de mayo de 2017), artículo periodístico. Véase el Anexo 3 para las referencias bibliográficas de fuentes no académicas.

10. Para que resulte más fácil apreciar las particularidades de la traducción de Juan Porras, ofrecemos igualmente la traducción de Luciana Possamay (Saint-Exupéry 1943/1975), redactada en español estándar. El contraste entre ambas traducciones permite evaluar mejor el alejamiento entre la versión en andaluz de Juan Porras y la traducción a la que el lector español está acostumbrado. SAInt-Exupéry, Antoine de (1943/1975): El Principito. (Traducido del francés por Luciana Possamay) Ciudad de México: Editores Mexicanos Unidos.

11. Véanse, entre otras muchas muestras de este tipo de reacciones, los siguientes artículos periodísticos: Cuerdo (2017), Anónimo (2017), Machuca (2017).

12. Narbona (2017), articulo periodístico.

13. Padres del Estatuto autonómico (30 de diciembre de 1981): Artículo 12.3.2. Estatuto de autonomía de Andalucía. Sevilla: Junta de Andalucía. Consultado el 4 de agosto 2017, <https://www. juntadeandalucia.es/html/especiales/estatuto/aj-nuevoestatuto-estatuto79dd.html?idSeccion=3\&i dApartado $=2 \&$ ctitulo $=1>$.

14. La vinculación de esta traducción con un proyecto político identitario ha sido reconocida por el propio traductor, quien declaró que esta nueva versión andaluza de Le Petit Prince pretendía, entre otras cosas, promover «la autoestima del pueblo andaluz» y dotarlo de «autoconciencia de identidad como pueblo singular» (Redacción de La Gaceta 2017; artículo periodístico). Resultan igualmente significativos, en este sentido, los apoyos recibidos por Juan Porras desde sectores vinculados al separatismo andaluz, como el Sindicato Andaluz de Trabajadores (Marroco 12 de mayo de 2017; artículo periodístico) o del movimiento Nación Andaluza, que emitió un comunicado en el que afirmaba que las críticas recibidas por el traductor eran resultado del desprecio «a las distintas culturas de la identidad nacional andaluza» (Comisión Permanente de Nación Andaluza 2017).

15. Este tipo de estrategias de hipervernacularización ya se han observado anteriormente en algunos políticos, que abandonan los rasgos característicos de su estrato sociocultural para acercarse electoralmente a las clases trabajadoras mediante el empleo de variantes vernaculares (Cutillas Espinosa, Hernández-Campoy et al. 2010: 31-52). Lempert y Siverstein (2012) observaron una estrategia similar en George W. Bush.

16. Nos referimos concretamente a la entrevista ofrecida en el programa La Brújula, de la emisora Onda Cero, el 11 de mayo de 2017 (Porras 2017).

17. «Lo que el análisis de los textos antiguos y la descripción de las hablas hispánicas no cultas de hoy nos muestran es lo mismo: una fuerte tendencia a la pérdida de la d, en casi cualquier posición de la palabra, solo refrenada por un impulso escolar y cultural. Prao, ná, perdío, toa, pare y mare, paré, usté, etc., no son, pues, “andalucismos" históricamente: han sido y son vulgarismos herederos de una antiquísima tendencia fonética castellana, que en Andalucía hallaron un especial caldo de cultivo» (Narbona Jiménez, Cano Aguilar et al. 1998: 76). Resulta difícil, pues, utilizar estos rasgos fonéticos para defender una supuesta esencia identitaria andaluza contrapuesta a la castellana, pues la repartición de muchos de ellos no es geográfica, sino social.

18. Aunque sea tradicional referirse a este fenómeno como lenición de la jota, lo cierto es que «no es exactamente que la "jota” castellana se haya relajado, o aflojado, en aspirada, como creen los profanos y algunos expertos, sino que las primitivas palatales, en el curso de sus modificaciones fonéticas, atraídas por la $h$ aspirada acabaron directamente en un sonido como este» (Narbona Jiménez, Cano Aguilar et al.: 1998: 68).

19. «Desde el Xix poner $-\mathrm{r}$ por -1 será uno de los rasgos recurrentes para caracterizar el habla andaluza, si bien hoy se ha demostrado su extensión por amplias zonas del español peninsular (además de su presencia americana). [...] El intercambio de $-\mathrm{r}$ y $-\mathrm{l}$ es, pues, otra vez un antiguo fenómeno castellano, quizá originario del centro peninsular» (Narbona Jiménez, Cano Aguilar et al. 1998: 76-77). Una vez más, nos encontramos con un rasgo fonético pretendidamente andaluz que, sin 
embargo, no tiene su origen histórico entre los hablantes andaluces, lo cual vuelve a poner en tela de juicio los intentos de deducir un supuesto carácter andaluz a partir de ciertos elementos lingüísticos.

20. La aparición de la velar sonora/g/ antes del diptongo /we/ (escrito la mayor parte del tiempo como $\langle$ ue) corresponde a un fenómeno propio del español medieval, en el que se presentaba la hipertrofia articulatoria del elemento velar de la /u/. En el caso de bueno > güeno, la /b/ es desplazada debido a un proceso de equivalencia acústica (contacto de dos sonoras).

21. Esta conjugación particular del verbo haber en los tiempos compuestos se ha observado igualmente en el español de Canarias, así como en el español de México, donde se registran igualmente formas como: nosotros hamos comido en lugar de nosotros hemos comido, o yo ha comido en lugar de yo he comido (Bills y Vigil 2008: 145; Escobar y Potowski 2015: 77).

\section{REFERENCIAS BIBLIOGRÁFICAS}

Anderson, Benedict (1983): Imagined Communities. Reflections on the Origin and Spread of Nationalism. Londres: Verso.

Berman, Antoine (1984): L'Épreuve de l'étranger: Culture et traduction dans l'Allemagne romantique. París: Gallimard.

Bills, Garland D. y Vigil, Neddy A. (2008): The Spanish Language of New Mexico and Southern Colorado. Albuquerque: University of New Mexico Press.

Bourdieu, Pierre (1982): Ce que parler veut dire. L'économie des échanges linguistiques. París: Fayard.

Bourdieu, Pierre (1984): Capital et marché linguistiques. Linguistische Berichte. 90:324.

BRAdFord, Lisa Rose (2005): La voz del poeta traductor en el Diario de poesía, Argentina 1986-presente. Estudios. Revista de investigaciones literarias y culturales. 25:303-331.

BRISSET, Annie (1990/2000): The search for a native language: translation and cultural identity. (Traducido del francés por Rosalind Gill y Roger Gannon) In: Lawrence Venuti, ed. The Translation Studies Reader. Londres/Nueva York: Routledge, 343-375.

Cano Aguilar, Rafael (2009): Lengua e identidad en Andalucía: visión desde la Historia. In: Antonio Narbona Jiménez, ed. La identidad lingüistica de Andalucía. Sevilla: Centro de Estudios Andaluces, 67-134.

Clyne, Michael G. (1992): Pluricentric Languages. Different Norms in Different Nations. Berlín: De Gruyter.

Coupland, Nikolas (2001): Dialect Stylizaton in Radio Talk. Language in Society. 30:345-375.

Cutillas Espinosa, Juan Antonio, Hernández-Campoy, Juan Manuel y Schilling-Estes, Natalie (2010): Hypervernacularisation and Speaker Design: A Case Study. Folia Lingüística. 44(1):31-52.

Del Pinto Artacho, Juan y Bericat, Eduardo (1998): Valores sociales en la cultura andaluza. Encuesta mundial de valores. Andalucía 1996. Madrid: Siglo xxi Editores.

ECKert, Penelope y Rickford, John, eds. (2001): Style and Sociolinguistic Variation. Cambridge: Cambridge University Press.

Escobar, Anna María y Ротоwsкi, Kim (2015): El español de los Estados Unidos. Cambridge: Cambridge University Press.

Fernando Lara, Luis (2007): Por una reconstrucción de la idea de la lengua española. Más allá de las fronteras instituidas. In: José Del VAlle, ed. La lengua, ¿patria común?: ideas e ideologías del español en el mundo hispánico. Madrid: Iberoamericana/Vervuert, 163-181.

Gentzler, Edwin (2008): Translation and Identity in the Americas. Londres/Nueva York: Routledge.

Herreras, José Carlos (2006): Lenguas y normalización en España. Madrid: Gredos.

Irvine, Judith T. (1989): When Talk Isn't Cheap: Language and Political Economy. American Ethnologist. 16:248-267.

Irvine, Judith T. y GaL, Susan (2000): Language Ideology and Linguistic Differentiation. In: Paul V. Kroskrity, ed. Regimes of Languages: Ideologies, Polities and Identities. Santa Fe: School of American Research Press, 35-84. 
Jiménez Bellver, Jorge (2012): Traducción e identidad, necesidad y deseo. Revista Puntoycoma. 127(22). Consultado el 21 de agosto de 2017, <http://ec.europa.eu/translation/bulletins/ puntoycoma/127/pyc1277_es.htm\#6>.

KLoss, Heinz (1967): Abstand Languages and Ausband Languages. Anthropological Linguistics. 9(7):29-41.

LAPESA, Rafael (1988): Historia de la lengua española. Madrid: Gredos.

Lempert, Michael y Silverstein, Michael (2012): Creatures of Politics: Media, Message, and the American Presidency. Bloomington: Indiana University Press.

MÉNDEZ, Elena (2003): El habla andaluza en los libros de texto escolares. Cauce. 27:207-230.

MÉndez, Elena (2009): La proyección social de la identidad lingüística de Andalucía. Medios de comunicación, enseñanza y política lingüística. In: Antonio NARbona JiménEz, ed. La identidad lingüistica de Andalucía. Sevilla: Centro de Estudios Andaluces, 213-322.

Milroy, James (1992): Language Variation and Change. Oxford: Blackwell.

Milroy, James (2001): Language ideologies and the consequences of standardization. Journal of Sociolinguistics. 5(4):530-550.

Montezanti, Miguel Ángel (2011): Prólogo. In: William Shakespeare. Sólo vos sos vos. Los sonetos de Shakespeare en traducción rioplatense. (Traducido del inglés por Miguel Ángel Montezanti) Mar del Plata: EUDEM, 9-30.

Morillo-Velarde, Ramón (2009): La identidad fónica de los andaluces. In: Antonio Narbona Jiménez, ed. La identidad lingüística de Andalucía. Sevilla: Centro de Estudios Andaluces, 135-209.

MunR, Rudolph (2013): Codifying linguistic standards in non-dominant varieties of pluricentric languages - adopting dominant or native norms? In: Rudophl Munr, Carla Amorós Negre y Carmen Fernández Juncal, eds. Exploring Linguistic Standards in Non-Dominant Varieties of Pluricentric Languages. Berna: Peter Lang, 11-44.

Narbona Jiménez, Antonio (2009): La identidad lingüística andaluza. In: Antonio Narbona Jiménez, ed. La identidad lingüística de Andalucía. Sevilla: Centro de Estudios Andaluces, 23-63.

Narbona Jiménez, Antonio, Cano Aguilar, Rafael y Morillo-Velarde, Ramón (1998): El español hablado en Andalucía. Barcelona: Ariel.

Narbona Jiménez, Antonio y Morillo-Velarce, Ramón (1987): Las hablas andaluzas. Córdoba: Caja de Ahorros de Córdoba.

Quilis, Antonio (1992): La lengua española en cuatro mundos. Madrid: Mapfre.

Schilling-Estes, Natalie (2002): Investigating Stylistic Variation. In: Jack K. Chambers, Peter J. Trudgill y Natalie Schilling-Estes, eds. The Handbook of Linguistic Variation and Change. Oxford: Blackwell, 375-401.

Sontag, Susan (1997): On Being Translated. RES: Anthropology and Aesthetics. 32:13-18.

Trudgill, Peter J. (1983): On Dialect: Social and Geographical Perspectives. Oxford: Blackwell.

Trudgill, Peter J. (2003): A Glossary of Sociolinguistics. Edinburgh: Edinburgh University Press.

Түмосzко, Maria (2010): The Space and Time of Activist Translation. In: Maria Ty moczko, ed. Translation, Resistance, Activism. Amherst/Boston: University Massachusetts Press, 227254.

Villena Ponsoda, Juan Andrés (2000): Identidad y variación lingüística: Prestigio nacional y lealtad vernacular en el español hablado de Andalucía. In: Georg Bossong y Francisco Báez DE Aguilar, eds. Identidades lingüísticas en la España autonómica. (Jornadas Hispánicas 1997 de la Sociedad Suiza de estudios Hispánicos, Zúrich, 21-22 de noviembre de 1997). Frankfurt/Madrid: Vervuert/Iberoamericana, 107-150.

Villena Ponsoda, Juan Andrés (2008): Divergencia dialectal en el español de Andalucía: El estándar regional y la nueva koiné meridional. In: Hans-Jörg DöHLa y Raquel MonteroMuÑoz, eds. Lenguas en diálogo. El iberorromance y su diversidad lingüística y literaria. Madrid/Frankfurt: Iberoamericana/Vervuert, 369-392.

Villena Ponsoda, Juan (2016): Variación lingüística y traducción. Por qué el traductor necesita del variacionista. In: Giovanni Caprara, Emilio Ortega Arjonilla y Juan Andrés 
Villena Ponsoda, eds. Variación lingüística, traducción y cultura: De la conceptualización a la práctica profesional. Berna: Peter Lang, 9-118.

Von Flotow-Evans, Luise (1991): Feminist Translation: Contexts, Practices and Theories. TTR. 4(2):69-85.

Von Flotow-Evans, Luise (1997): Translation and gender: translating in the era of feminism. Manchester: St. Jerome.

Woolard, Kathryn (1998): Introduction: Language Ideology as a Field of Inquiry. In: Bambi B. Schieffelin, Kathryn A. Woolard y Paul V. Kroskrity, eds. Language Ideology: Practice and Theory. Oxford/Nueva York: Oxford University Press, 3-47.

Woolard, Kathryn (2007): La autoridad lingüística del español y las ideologías de la autenticidad y el anonimato. In: José del VAlLe, ed. La lengua, ¿patria común?: ideas e ideologías del español en el mundo hispánico. Madrid/Frankfurt: Iberoamericana/Vervuert, 129-142.

\section{ANEXOS}

Anexo 1: Características fonéticas de Er Prinzipito

\begin{tabular}{|l|l|l|}
\hline \multicolumn{1}{|c|}{$\begin{array}{c}\text { Le Petit Prince } \\
\text { (Saint-Exupéry 1943/1972) }\end{array}$} & \multicolumn{1}{|c|}{$\begin{array}{c}\text { Er Prinzipito } \\
\text { (Saint-Exupéry 1943/2017; } \\
\text { traducido por Juan Porras) }\end{array}$} & $\begin{array}{c}\text { El Principito } \\
\text { (Saint-Exupéry 1943/1975; } \\
\text { traducido por Luciana } \\
\text { Possamay) }\end{array}$ \\
\hline Aspiración de las eses en final de sílaba o palabra (reflejada mediante el grafema $\langle$ h〉)
\end{tabular}




\begin{tabular}{|c|c|c|}
\hline \multicolumn{3}{|c|}{ Intercambio de los fonemas $/ r / y / l /$ a final de sílaba o palabra ${ }^{19}$} \\
\hline $\begin{array}{l}\text { Chaque jour j'apprenais quelque } \\
\text { chose sur la planète. } \\
\text { (p. 21) }\end{array}$ & $\begin{array}{l}\text { A ka día m'enteraba d'argo } \\
\text { nuebo zobr'er planeta. } \\
\text { (p. 21) }\end{array}$ & $\begin{array}{l}\text { Cada día aprendía algo nuevo } \\
\text { sobre el planeta. } \\
\text { (p. 25) }\end{array}$ \\
\hline \multicolumn{3}{|c|}{ Pronunciación del fonema /r/mediante aspiración } \\
\hline $\begin{array}{l}\text { les jambes pendantes } \\
\text { (p. 95) }\end{array}$ & $\begin{array}{l}\text { Lah piehnah korgando } \\
\text { (p. 83) }\end{array}$ & $\begin{array}{l}\text { Las piernas colgando } \\
\text { (p. 87) }\end{array}$ \\
\hline \multicolumn{3}{|c|}{$\begin{array}{l}\text { Geminación por el encuentro del fonema /r/final de un infinitivo y el fonema } / l / \text { inicial de un } \\
\text { pronombre personal }\end{array}$} \\
\hline $\begin{array}{l}\text { pour avertir mes amis }[\ldots] \\
\text { (p. 24) }\end{array}$ & $\begin{array}{l}\text { pa prebenil-leh a mih amigoh } \\
[\ldots] . \text { (p. } 24)\end{array}$ & $\begin{array}{l}\text { con el objeto de prevenir a mis } \\
\text { amigos [...]. (p. 28) }\end{array}$ \\
\hline \multicolumn{3}{|l|}{ Intercambio de los fonemas $/ n / y / r /$} \\
\hline $\begin{array}{l}\text { avec moi } \\
\text { (p. } 8)\end{array}$ & $\begin{array}{l}\text { kormigo } \\
\text { (p. 11) }\end{array}$ & $\begin{array}{l}\text { conmigo } \\
\text { (p. 14) }\end{array}$ \\
\hline $\begin{array}{l}\text { avec mon renard } \\
\text { (p. 89) }\end{array}$ & $\begin{array}{l}\text { kor mi zorro } \\
\text { (p. 78) }\end{array}$ & $\begin{array}{l}\text { con mi zorro } \\
\text { (p. } 82 \text { ) }\end{array}$ \\
\hline \multicolumn{3}{|c|}{ Conversión del fonema /e/ en / i/ en posición átona } \\
\hline $\begin{array}{l}\text { j’ai réussi } \\
\text { (p. 5) }\end{array}$ & $\begin{array}{l}\text { konziguí } \\
\text { (p. 9) }\end{array}$ & $\begin{array}{l}\text { logré } \\
(\mathrm{p} .12)\end{array}$ \\
\hline $\begin{array}{l}\text { après } \\
\text { (p. } 78)\end{array}$ & $\begin{array}{l}\text { dihpuéh } \\
\text { (p. 67) }\end{array}$ & \begin{tabular}{|l} 
después \\
(p. 71)
\end{tabular} \\
\hline $\begin{array}{l}\text { se réveiller } \\
\text { (p. 22) }\end{array}$ & $\begin{array}{l}\text { dihpertarze } \\
\text { (p. 22) }\end{array}$ & $\begin{array}{l}\text { despertarse } \\
\text { (p. 26) }\end{array}$ \\
\hline \multicolumn{3}{|c|}{ Conversión del fonema /o/ en /u/ en posición átona } \\
\hline $\begin{array}{l}\text { la cheville } \\
\text { (p. 70) }\end{array}$ & $\begin{array}{l}\text { er tubiyo } \\
\text { (p. 60) }\end{array}$ & $\begin{array}{l}\text { el tobillo } \\
\text { (p. 64) }\end{array}$ \\
\hline $\begin{array}{l}\text { de vie ou de mort } \\
\text { (p. } 8 \text { ) }\end{array}$ & $\begin{array}{l}\text { de bía u muerte } \\
\text { (p. 11) }\end{array}$ & $\begin{array}{l}\text { de vida o muerte } \\
\text { (p. 14) }\end{array}$ \\
\hline \multicolumn{3}{|c|}{ Conversión del fonema /i/ en /e/ en posición átona } \\
\hline $\begin{array}{l}\text { intelligent } \\
\text { (p. 49) }\end{array}$ & \begin{tabular}{|l} 
enteligente \\
(p. 44)
\end{tabular} & $\begin{array}{l}\text { inteligente } \\
\text { (p. 47) }\end{array}$ \\
\hline \multicolumn{3}{|c|}{ Aparición de la velar sonora $/ g /$ antes del diptongo $/ u e^{20}($ escrito como $\langle u e\rangle)$} \\
\hline $\begin{array}{l}\text { Bonjour } \\
\text { (p. 77) }\end{array}$ & $\begin{array}{l}\text { Guenoh díah } \\
\text { (p. 66) }\end{array}$ & $\begin{array}{l}\text { Buenos días } \\
\text { (p. 70) }\end{array}$ \\
\hline $\begin{array}{l}\text { se retourna } \\
\text { (p. 77) }\end{array}$ & $\begin{array}{l}\text { se dio la guerta } \\
\text { (p. 66) }\end{array}$ & $\begin{array}{l}\text { se volvió } \\
\text { (p. 70) }\end{array}$ \\
\hline \multicolumn{3}{|c|}{ Pronunciación de los grafemas iniciales $\langle h\rangle,\langle b\rangle$ o $\langle v\rangle$ mediante el fonema $/ g /$} \\
\hline $\begin{array}{l}\text { Mais le renard revint à son idée. } \\
\text { (p. 80) }\end{array}$ & $\begin{array}{l}\text { Pero er zorro gorbió a zu idea. } \\
\text { (p. 68) }\end{array}$ & $\begin{array}{l}\text { Pero el zorro volvió a su idea. } \\
\text { (p. 72) }\end{array}$ \\
\hline \multicolumn{3}{|c|}{ Anteposición del sonido /g/a palabra que empieza por vocal } \\
\hline $\begin{array}{l}\text { il n’a jamais respiré une fleur. } \\
\text { (p. 30) }\end{array}$ & $\begin{array}{l}\text { Er nunka a golío una flo. } \\
\text { (p. 29) }\end{array}$ & $\begin{array}{l}\text { Jamás ha aspirado el aroma de } \\
\text { una flor. (p. } 32 \text { ) }\end{array}$ \\
\hline \multicolumn{3}{|l|}{ Pérdida del fonema inicial /a/ } \\
\hline $\begin{array}{l}\text { Le puits que nous avions atteint } \\
\text { (p. 90) }\end{array}$ & $\begin{array}{l}\text { Er pozo ar ke bíamoh yegao } \\
{[\ldots] .(\text { p. } 80)}\end{array}$ & $\begin{array}{l}\text { El pozo que encontramos } \\
{[\ldots] . \text { (p. 83) }}\end{array}$ \\
\hline
\end{tabular}




\begin{tabular}{|l|l|l|}
\hline \multicolumn{4}{|l|}{ Adición del sonido /a/ en el inicio de la palabra } \\
\hline $\begin{array}{l}\text { je hissai le seau } \\
\text { (p. 91) }\end{array}$ & $\begin{array}{l}\text { l'alebanté er kubo } \\
\text { (p. 80) }\end{array}$ & $\begin{array}{l}\text { subí el cubo } \\
\text { (p. 84) }\end{array}$ \\
\hline $\begin{array}{l}\text { je veux redescendre } \\
\text { (p. 96) }\end{array}$ & $\begin{array}{l}\text { kiero abaharme otra beh } \\
\text { (p. 84) }\end{array}$ & $\begin{array}{l}\text { quiero bajarme } \\
\text { (p. 88) }\end{array}$ \\
\hline $\begin{array}{l}\text { Ensuite } \\
\text { (p. 5) }\end{array}$ & $\begin{array}{l}\text { Aluego } \\
\text { (p. 9) }\end{array}$ & $\begin{array}{l}\text { Entonces } \\
\text { (p. 12) }\end{array}$ \\
\hline $\begin{array}{l}\text { racines } \\
\text { (p. 72) }\end{array}$ & $\begin{array}{l}\text { arraízeh } \\
\text { (p. 62) }\end{array}$ & $\begin{array}{l}\text { raíces } \\
\text { (p. 65) }\end{array}$ \\
\hline Cambio del sonido /g/ sordo por el fonema /b/ \\
\hline $\begin{array}{l}\text { aiguilleur } \\
\text { (p. 84) }\end{array}$ & $\begin{array}{l}\text { guardabuhah } \\
\text { (p. 74) }\end{array}$ & $\begin{array}{l}\text { guardagujas } \\
\text { (p. 78) }\end{array}$ \\
\hline
\end{tabular}

Anexo 2: Características morfosintácticas de Er Prinzipito

\begin{tabular}{|c|c|c|}
\hline $\begin{array}{c}\text { Le Petit Prince } \\
\text { (Saint-Exupéry 1943/1972) }\end{array}$ & $\begin{array}{l}\text { Er Prinzipito } \\
\text { (Saint-Exupéry 1943/2017; } \\
\text { traducido por Juan Porras) }\end{array}$ & $\begin{array}{c}\text { El Principito } \\
\text { (Saint-Exupéry 1943/1975; } \\
\text { traducido por Luciana } \\
\text { Possamay) }\end{array}$ \\
\hline \multicolumn{3}{|c|}{ Particularidades en la conjugación de los verbos auxiliares en los tiempos compuestos } \\
\hline $\begin{array}{l}\text { J'ai connu } \\
\text { (p. 24) }\end{array}$ & $\begin{array}{l}\text { Yo a konozíio } \\
\text { (p. 24) }\end{array}$ & $\begin{array}{l}\text { Conozco } \\
\text { (p. 27) }\end{array}$ \\
\hline $\begin{array}{l}\text { J'ai essayé } \\
\text { (p. 24) }\end{array}$ & $\begin{array}{l}\text { Yo a intentao } \\
\text { (p. 24) }\end{array}$ & $\begin{array}{l}\text { He tratado } \\
\text { (p. 28) }\end{array}$ \\
\hline $\begin{array}{l}\text { J'aurais aimé commencer cette } \\
\text { histoire }[\ldots . . \\
\text { (p. 19) }\end{array}$ & $\begin{array}{l}\text { Me fuera guhtao de empezà } \\
\text { ehta ihtoria }[\ldots] . \\
\text { (p. 20) }\end{array}$ & $\begin{array}{l}\text { Me hubiera gustado comenzar } \\
\text { esta historia }[\ldots] \text {. } \\
\text { (p. 24) }\end{array}$ \\
\hline $\begin{array}{l}\text { ça aurait eu l'air beaucoup plus } \\
\text { vrai. } \\
\text { (p. 19) }\end{array}$ & $\begin{array}{l}\text { le fuera parezío ehto munxo } \\
\text { mah de berdá. } \\
\text { (p. 20) }\end{array}$ & $\begin{array}{l}\text { esto hubiera sonado mucho más } \\
\text { verdadero. } \\
\text { (p. 24) }\end{array}$ \\
\hline $\begin{array}{l}\text { de nouveau, s'était assis auprès } \\
\text { de moi. } \\
\text { (p. 92) }\end{array}$ & $\begin{array}{l}\text { ke z'iba guerto a zentà otra beh } \\
\text { a la bera mía. } \\
\text { (p. } 81 \text { ) }\end{array}$ & $\begin{array}{l}\text { nuevamente se había sentado } \\
\text { junto a mí. } \\
\text { (p. 86) }\end{array}$ \\
\hline \multicolumn{3}{|c|}{$\begin{array}{l}\text { Sustitución de vosotros ( } y \text { sus pronombres átonos correspondientes) por uhtedeh } \\
\text { (y sus pronombres átonos correspondientes) }\end{array}$} \\
\hline $\begin{array}{l}\text { Pour vous qui aimez aussi le } \\
\text { petit prince }[\ldots . .] \\
\text { (p. 104) }\end{array}$ & $\begin{array}{l}\text { Pa uhtedeh, ke tambié'hkeréih } \\
\text { ar prinzipito }[\ldots . . \\
\text { (p. 93) }\end{array}$ & $\begin{array}{l}\text { Para vosotros, que también } \\
\text { amáis al principito [...]. } \\
\text { (p. 97) }\end{array}$ \\
\hline $\begin{array}{l}\text { Si alors un enfant vient à vous } \\
{[\ldots] . \text { (p. 105) }}\end{array}$ & $\begin{array}{l}\text { Zi entoze un niño ze viene pa } \\
\text { uhtedeh [...]. (p. 95) }\end{array}$ & $\begin{array}{l}\text { Si entonces un niño va hacia } \\
\text { vosotros [...]. (p. 99) }\end{array}$ \\
\hline $\begin{array}{l}\text { s'il vous arrive de passer par là } \\
{[\ldots] .(\text { p. 105) }}\end{array}$ & $\begin{array}{l}\text { zi ar kazo ze yegáraih a pazà } \\
\text { porahkí }[\ldots] . \text { (p. 95) }\end{array}$ & $\begin{array}{l}\text { si llegáis a pasar por allí [...]. } \\
\text { (p. 99) }\end{array}$ \\
\hline $\begin{array}{l}\text { Alors vous imaginez ma } \\
\text { surprise. } \\
\text { (p. } 8 \text { ) }\end{array}$ & $\begin{array}{l}\text { Figurarze entoze mi zorpreza } \\
{[\ldots]} \\
\text { (p. 11) }\end{array}$ & $\begin{array}{l}\text { En tales circunstancias ya } \\
\text { pueden imaginarse }[. . .] . \\
\text { (p. 14) }\end{array}$ \\
\hline $\begin{array}{l}\text { Demandez-vous }[\ldots] \text {. } \\
\text { (p. 105) }\end{array}$ & $\begin{array}{l}\text { Preguntarze }[\ldots] . \\
\text { (p. 93) }\end{array}$ & $\begin{array}{l}\text { Pregunten }[\ldots] \\
\text { (p. 97) }\end{array}$ \\
\hline
\end{tabular}




\begin{tabular}{|c|c|c|}
\hline \multicolumn{3}{|l|}{ Abundancia de sufijos diminutivos } \\
\hline $\begin{array}{l}\text { petit } \\
\text { (p.X) }\end{array}$ & $\begin{array}{l}\text { xikitiyoh } \\
\text { (p. 22) }\end{array}$ & $\begin{array}{l}\text { pequeñitos } \\
\text { (p. 25) }\end{array}$ \\
\hline $\begin{array}{l}\text { dès qu'on a su la reconnaître } \\
{[\ldots] . \text { (p. 23) }}\end{array}$ & $\begin{array}{l}\text { En kuantito ze la puea rekonocè } \\
{[\ldots] .(\text { p. 22) }}\end{array}$ & $\begin{array}{l}\text { En cuanto se la reconoce }[\ldots] . \\
\text { (p. 25) }\end{array}$ \\
\hline $\begin{array}{l}\text { peu à peu } \\
\text { (p. 26) }\end{array}$ & $\begin{array}{l}\text { pokiy'a poko } \\
\text { (p. 26) }\end{array}$ & $\begin{array}{l}\text { poco a poco } \\
\text { (p. 28) }\end{array}$ \\
\hline $\begin{array}{l}\text { jeunes } \\
\text { (p. 23) }\end{array}$ & $\begin{array}{l}\text { xikueliyoh } \\
\text { (p. 24) }\end{array}$ & $\begin{array}{l}\text { pequeñas } \\
\text { (p. 27) }\end{array}$ \\
\hline $\begin{array}{l}\text { comme moi-même } \\
\text { (p. 24) }\end{array}$ & $\begin{array}{l}\text { komo a mí mihmito } \\
\text { (p. 24) }\end{array}$ & $\begin{array}{l}\text { al igual que a mí mismo } \\
\text { (p. 28) }\end{array}$ \\
\hline $\begin{array}{l}\text { Il ne répondit rien à ma } \\
\text { question } \\
\text { (p. 97) }\end{array}$ & $\begin{array}{l}\text { No kontehtó naíta a mi } \\
\text { pregunta (p. } \overline{84)}\end{array}$ & $\begin{array}{l}\text { No respondió respecto de mi } \\
\text { pregunta } \\
\text { (p. 90) }\end{array}$ \\
\hline $\begin{array}{l}\text { avec un peu de mauvaise } \\
\text { humeur (p. 9) }\end{array}$ & $\begin{array}{l}\text { argo enritaete } \\
\text { (p. 12) }\end{array}$ & $\begin{array}{l}\text { Con un poco de mal humor } \\
\text { (p. 16) }\end{array}$ \\
\hline \multicolumn{3}{|c|}{ Presencia de la preposición de tras verbos que no la rigen } \\
\hline $\begin{array}{l}\text { J'ai réussi }[\ldots] \text { à tracer mon } \\
\text { premier dessin (p. 6) }\end{array}$ & $\begin{array}{l}\text { Konziguí de garabateá [...] mi } \\
\text { primer dibuho (p. 9) }\end{array}$ & $\begin{array}{l}\text { Logré trazar mi primer dibujo } \\
\text { (p. 12) }\end{array}$ \\
\hline $\begin{array}{l}\text { L'idée du troupeau d'éléphants } \\
\text { fit rire le petit prince. } \\
\text { (p. 21) }\end{array}$ & $\begin{array}{l}\text { La idea d'una trupe d'alefanteh } \\
\text { hizo de reírze ar prinzipito. } \\
\text { (p. } 22 \text { ) }\end{array}$ & $\begin{array}{l}\text { La idea de la manada de } \\
\text { elefantes le hizo mucha gracia. } \\
\text { (p. 25) }\end{array}$ \\
\hline $\begin{array}{l}{[\ldots] \text { ils la font éclater. }} \\
\text { (p. 23) }\end{array}$ & $\begin{array}{l}\text { [...] lo hazen de reventa } \\
\text { (p. 23) }\end{array}$ & $\begin{array}{l}{[\ldots] \text { lo hacen estallar }} \\
\text { (p. 26) }\end{array}$ \\
\hline \multicolumn{3}{|l|}{ Uso de la preposición ca (casa) } \\
\hline $\begin{array}{l}\text { Et les routes vont toutes chez les } \\
\text { hommes. } \\
\text { (p. 75) }\end{array}$ & $\begin{array}{l}\text { I to lah bereah yeban an ka'e } \\
\text { loh z'ombreh } \\
\text { (p. 64) }\end{array}$ & $\begin{array}{l}\text { Y todos los caminos van hacia } \\
\text { parajes habitados por los } \\
\text { hombres (p. 68) }\end{array}$ \\
\hline \multicolumn{3}{|c|}{ Cambio de orden en los pronombres personales átonos } \\
\hline $\begin{array}{l}\text { Mon petit bonhomme ne me } \\
\text { semblait ni égaré, ni mort de } \\
\text { fatigue. (p. 9) }\end{array}$ & $\begin{array}{l}\text { Er xabaliyo no me ze hazía ni } \\
\text { perdío, ni guano. } \\
\text { (p. 12) }\end{array}$ & $\begin{array}{l}\text { Mi pequeño hombrecito no se } \\
\text { me hacía ni perdido ni muerto } \\
\text { de cansancio. (p. 14) }\end{array}$ \\
\hline $\begin{array}{l}\text { j’ai oublié [...]. } \\
\text { (p. 104) }\end{array}$ & $\begin{array}{l}\text { Me z’orbió }[\ldots] . \\
\text { (p. 93) }\end{array}$ & $\begin{array}{l}\text { Olvidé }[\ldots] \\
\text { (p. 97) }\end{array}$ \\
\hline \multicolumn{3}{|l|}{ Confusión de prefijos } \\
\hline $\begin{array}{l}{[\ldots] \text { afin que les grandes }} \\
\text { personnes puissent compren- } \\
\text { dre. } \\
\text { (p. 6) }\end{array}$ & $\begin{array}{l}{[\ldots] \text { perkurando de ke lah }} \\
\text { perzonah mayoreh lo entendie- } \\
\text { ran. (p. 10) }\end{array}$ & $\begin{array}{l}{[\ldots] \text { a fin de que los personajes }} \\
\text { mayores pudieran comprender. } \\
\text { (p. 12) }\end{array}$ \\
\hline \multicolumn{3}{|l|}{ Gerundios preposicionales } \\
\hline $\begin{array}{l}\text { ayant ouvert son registre [...]. } \\
\text { (p. 63) }\end{array}$ & $\frac{\text { en abiendo abierto zu rehihtro }}{[\ldots] .(\text { p. 55) }}$ & $\begin{array}{l}\text { Abrió su registro }[\ldots] . \\
\text { (p. 59) }\end{array}$ \\
\hline $\begin{array}{l}\text { Et quand l'heure du départ fut } \\
\text { proche }[\ldots] . \text { (p. } 82 \text { ) }\end{array}$ & $\begin{array}{l}\text { En siendo ya kuazi la ora pa } \\
\text { irze [...]. (p. 70) }\end{array}$ & $\begin{array}{l}\text { Cuando llegó el día de la } \\
\text { separación [...]. (p. 74) }\end{array}$ \\
\hline
\end{tabular}




\section{Anexo 3: Fuentes no académicas (artículos periodísticos, entrevistas, sitios Web)}

Anónimo (14 de mayo de 2017): Un marciano en el planeta B-612 («Zeiciento doce»). La Razón. Consultado el 3 de octubre de 2017, <https://www.larazon.es/cultura/un-marciano-en-el-planeta-b-612-zeiciento-doce-IB15140282>.

Comisión Permanente de Nación Andaluza (15 de mayo de 2017): Nación Andaluza en defensa del andaluz y del movimiento andalófilo. Nación Andaluza. Consultado el 17 de septiembre de 2017, <https://nacionandaluza.org/2017/05/15/nacion-andaluza-en-defensa-del-andaluz-y-delmovimiento-andalofilo/>.

Cuerdo, Cecilia (10 de mayo de 2017): Ozú con 'Er prinzipito'. El Diario Montañés. Consultado el 3 de octubre de 2017, <https://www.eldiariomontanes.es/sociedad/201705/10/ prinzipito-20170510114326.html>.

Machuca, Félix J. (10 de mayo de 2017): Er Prinzipito de Huan Porrah. ABC de Sevilla. 14. Consultado el 4 de octubre de 2017, <http://hemeroteca.abcdesevilla.es/nav/Navigate.exe/hemeroteca/sevilla/ abc.sevilla/2017/05/10/014.htm>.

Marroco, Antonio (12 de mayo de 2017): El SAT impulsa la edición en «andalú» de El Principito. $A B C$ de Sevilla. Consultado el 4 de octubre de 2017, <https://sevilla.abc.es/andalucia/seviimpulsa-edicion-andalu-prinzipito-201705081327_noticia.html >.

Marroco, Antonio (14 de mayo de 2017): Así se lee El Principito en andaluz. ABC de Sevilla. Consultado el 2 de octubre de 2017, <https://sevilla.abc.es/andalucia/sevi-principito-andaluz-perdonninoh-dabel-le-dedikao-ehte-libro-201705121701_noticia.html>.

Narbona, Antonio (16 de mayo de 2017): 'Er Prinzipito'. Diario de Sevilla. Consultado el 2 de octubre de 2017, <https:/www.diariodesevilla.es/opinion/tribuna/Er-Prinzipito_0_1136286817.html>.

Porras, Juan (11 de mayo de 2017): Juan Porras Blanco defiende el andaluz como idioma en 'Er Prinzipito'. (Entrevistado por David Del Cura) La Brújula: Onda Cero. Consultado el 21 de agosto de 2017, <https://www.ondacero.es/programas/la-brujula/audios-podcast/entrevistas/ juan-porras-blanco-defiende-el-andaluz-como-idioma-en-er-prinzipito_201705115914c44c0cf 2161ded9a54f2.html>.

Redacción de La GaCETA (8 de mayo de 2017): Así es 'Huan Porrah Blanko', autor de 'Er Principito'. La Gaceta. Consultado el 15 de septiembre de 2017, <https:/gaceta.es/noticias/huan-porrahblanko-autor-er-principito-08052017-1149/\#>. 